\title{
Effectiveness of Implementing a Tutor Training Workshop for Problem Based Learning Class Tutors at the Faculty of Medicine, Suez Canal University
}

Marwa Ahmed Abd El-Aziz El Naggar ${ }^{1 *}$, Fathi Abdel Hamid Maklady², Adel Morshedy Hamam ${ }^{3}$ and Aziza Sayed Omar

${ }^{1}$ Medical Education Department, Faculty of Medicine, Suez Canal University, Egypt

${ }^{2}$ Cardiology, Faculty of Medicine, Suez Canal University, Egypt

${ }^{3}$ Orthopedics, Faculty of Medicine, Suez Canal University, Egypt

${ }^{4}$ Rheumatology and Rehabilitation, Faculty of Medicine, Suez Canal University, Egypt

\begin{abstract}
Background: The Faculty of Medicine, Suez Canal University was established to become the first ProblemBased Learning school in the Middle East. In a problem-based-learning tutor should know well both the content of the problems and how to facilitate the small-group learning process, A tutor training program needs to be developed that will morph tutors from teachers to facilitators.
\end{abstract}

Aim: The aim of this study was to measure the educational effectiveness of implementing a tutor training workshop at The Faculty of Medicine, Suez Canal University.

Methodology: A quasi-experimental, Pre-program/post-program non-equivalent comparison group design was applied in this study. The target population was randomly assigned to intervention and control groups, a total number of 28 tutors in each group. The study passed through three stages: "preparatory", "design" and "implementation and evaluation" stages. The data was collected by: needs assessment questionnaire, tutors self-satisfaction questionnaire, student satisfaction questionnaire administered before and after the implementation, questionnaire to assess tutors' and students' satisfaction with tutors' performance. Six steps approach to curriculum development was used as a method for planning and implementing the tutor training workshop. The first three levels of Kirkpatrick's model of evaluation of educational interventions (reaction, learning, and behavior) were applied in this study to evaluate effectiveness of the workshop.

Results: Results showed an overall tutor satisfaction with the training workshop. More than $70 \%$ of workshop participants agreed that the workshop furthered their understanding of PBL as educational strategy and their role as tutors. The mean of the pretest was 5.42 and the mean of post-test was 7.1 , the results also shows that there was a statically significance difference between the results of the pre-and the post-tests for the workshop at $p \leq$ 0.05. Results also showed improvement of the intervention group performance. The average score for the overall performance of the tutor was $(7.67 \pm 1.20)$ in the intervention group compared with the control group $(6.54 \pm 2.02)$.

Conclusion: The study concluded that tutor training workshop was effective in improving tutor facilitation skills in the areas of constructive active learning, self- directed learning, collaborative learning, intra-personal behavior as tutor, and increase educational effectiveness of the PBL sessions from students' point of views. Tutor training workshop enhanced tutor performance in intervention group compared to the control group. The tutor training workshop increases tutors' self satisfaction with their performance and enhances students' satisfaction with tutor performance. Tutor training was effective as it incorporated adult learning principles (was relevant and interactive) experiential learning; arose from needs assessments; rewarded participation; encourage active participation; had clear goals and a theoretical framework

Keywords: Tutor training; PBL; Tutor; Kirkpatrick' model; Faculty development workshop; DELPHI

\section{Introduction}

The Faculty of Medicine, Suez Canal University (FOM-SCU) was established in 1978 to become the first Problem-Based, community oriented/based and student-centered school in the Middle East. The main objective of its establishment was to meet the health needs of the four Suez Canal Governorates and Sinai [1]. Problem - based learning (PBL) can be defined as "a method of learning in which the learners first encounter a problem, followed by a systematic, student-centered enquiry process [2].

PBL is older than formal education itself; students' learning is initiated by an authentic problem or puzzle that the learner wants to solve and find solutions [3]. It is one of the innovative themes in medical education [4]. In the inquiry problem-based learning approach, complex, real-world problems are used to motivate students to identify, generate hypothesis, use clinical reasoning and research the concepts and principles they strive to know to work through those problems. Students work in small learning teams from 8 to 10 students in each tutorial, bringing together general transferrable skill

*Corresponding author: Marwa Ahmed Abd El-Aziz El Naggar, Medical Education Department, Faculty of Medicine, Suez Canal University, Egypt, Tel: 0201002874739; E-mail: marwanagar@yahoo.com

Received May 15, 2013; Accepted June 25, 2013; Published June 27, 2013

Citation: El-Aziz El Naggar MAA, Maklady FAH, Hamam AM, Omar AS (2013) Effectiveness of Implementing a Tutor Training Workshop for Problem Based Learning Class Tutors at the Faculty of Medicine, Suez Canal University. Intel Prop Rights 1: 104. doi:10.4172/2375-4516.1000104

Copyright: @ 2013 El-Aziz El Naggar MAA, et al. This is an open-access article distributed under the terms of the Creative Commons Attribution License, which permits unrestricted use, distribution, and reproduction in any medium, provided the original author and source are credited. 
as communicating, integrating information and problem solving skills (Figure 1) [5,6].

In 2000, Harden and Crosby [7] have described the new roles of the teacher they stated that they are "providing information, role modeling, mentoring and facilitating, assessing and evaluating and planning. Each of the six roles described can be subdivided into two roles, making a total of 12 roles" as illustrated in Figure 2.

Harden and his colleague have been identified the twelve roles of medical teacher, they grouped them in six areas in the model presented:

a. The information provider as in expository educational method "lecture", and in the clinical context

b. The role model, and in formal teaching settings

c. The facilitator as a mentor and learning facilitator as PBL tutor

d. The student assessor (formative and summative assessment) and curriculum evaluator (process and outcomes)

e. the curriculum and course planner in his specialty and

f. The resource material creator or designer, and study guide producer or tutor guide producer.

As we can see that the functions are divided in two categories, one require more medical expertise and the others more educational expertise, some roles need more direct face-to-face contact with students and others less.

Tutors are essential for PBL tutorials educational process, its facilitation and enrichment [8]. Each tutorial group is assigned a trained tutor. The role of the tutors is subtle and restricted to facilitation of students' activities and clarifying difficult terminology and students' motivation to solve the given problem through deep self-directed learning [9]. The whole process is subjected to careful planning including selection, prioritization, organization and sequence of problems, adequate learning resources, and staff (Figure 3).

The characteristics of good tutor can be viewed in three domains knowledge, skills and attitude. The terms of knowledge the good tutor should know the goals of the curriculum, the learning objectives of the module that he is tutoring in, the available learning resources, principles of assessment, and group dynamics. His set of skills should include facilitating learning, problem solving, critical thinking, group dynamics or conflict resolution and assessment of the students individually and as group; in order to be successful, the tutor should have correct attitudes. He should be comfortable with the PBL philosophy and adopt a positive attitude toward PBL as a teaching

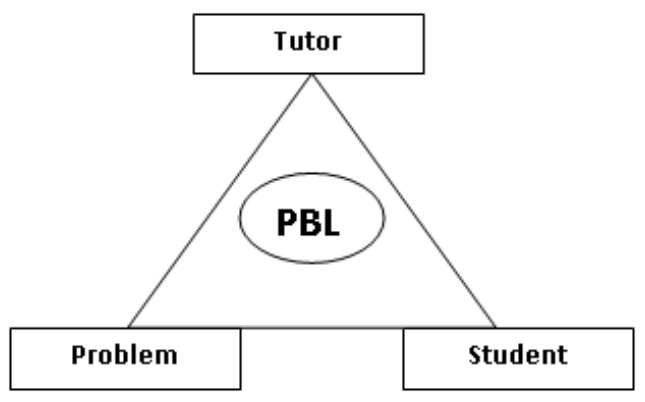

Figure 1: Angles of success in PBL.

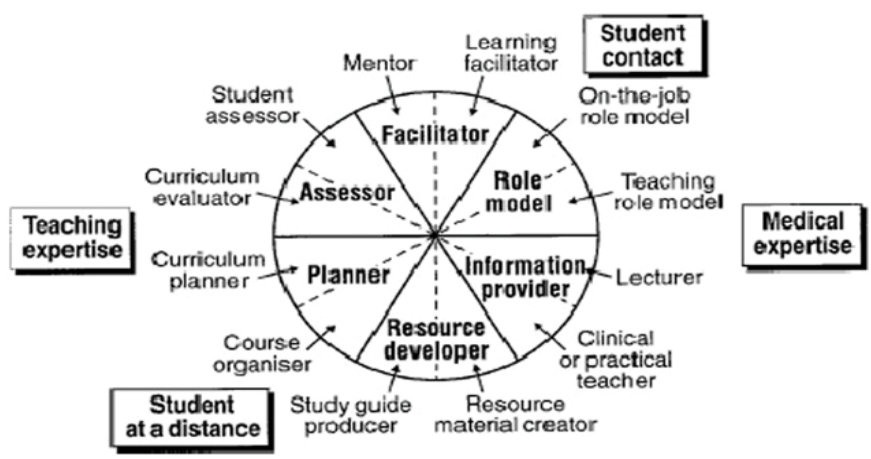

Figure 2: The twelve roles of the medical teacher, from content expert to professional role model.

method. He should shift his mind from being a "sag on center stage" to be "guide on the side" [10].

\section{Tutor training}

Faculty development: Faculty development is the broad range of activities that institutions use to recruit, renew or assist faculty in their functions and roles, and includes initiatives and activities (seminars or workshop) designed to improve the performance of faculty members in teaching, research and administration. Also Faculty development can be defined as a planned program to prepare institutions and faculty members for their academic roles (teaching, research, administration, writing and career management), it is also meant to improve practice and manage change in institutional curriculum or learning strategies, by enhancing individual strengths and abilities as well as organizational capacities and culture [11].

Planning and implementing a tutor training (Faculty Development) program: a six step-step approach [12].
A. Planning faculty development (Steps 1-3);
B. Implementation (Steps 4-5) and, finally;
C. Evaluation and feedback (Step 6).

\section{Planning faculty development (Steps 1-3):}

Step 1: Problem identification and general needs assessment: The first step is to agree on the purpose of the proposed faculty development (i.e. identify the problem) and the broad aim in terms of the institution, particular disciplines and individual faculty members (i.e. a general needs assessment) [13].

Step 2: Needs assessment of target participants: Having agreed on the general purpose of the faculty development programme, the needs of individual faculty members, disciplines and the institution should be identified. Critical questions at this stage would include: For whom is the faculty development? Why do they need faculty development? What is their current level of knowledge, skills and attitudes? Is faculty development voluntary or mandatory? What barriers exist? How do we overcome them?

A possible way to identify a cognitive deficit might be to measure faculty members' 'tacit' knowledge and understanding of teaching and learning concepts. You may have to develop your own tools, which ideally should promote self-assessment [12].

Step 3: Appropriate goals and specific measurable outcomes: 


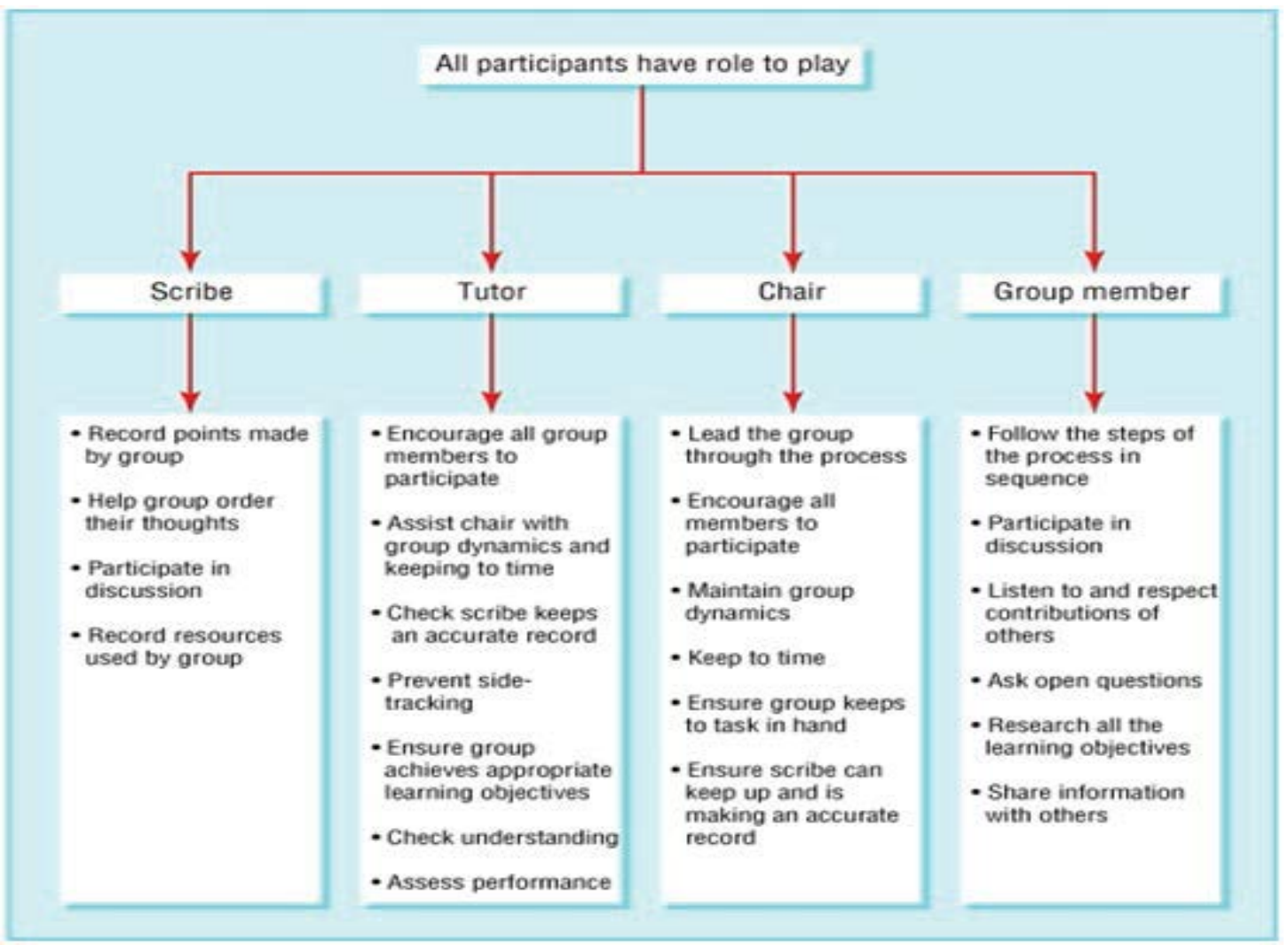

Figure 3: Roles of participants in a PBL tutorial.

Questions at this point may include: What knowledge, skills and attitudes need to be achieved through faculty development? Is it possible to measure improved student learning or improved patient care? What tools are at our disposable to measure the proposed outcomes?

Realistic and measurable outcomes may then include:

- Individual competencies in terms of cognitive (knowledge), affective (attitudinal) and psychomotor (skills and performance) development.

- The learning 'process' (e.g. small group facilitation; reflective teaching).

- Educational (e.g. better student assessment) or clinical (e.g. improved communication with patients) benefits [13].

\section{Implementation (Steps 4 and 5):}

Step 4: Educational strategies: Educational strategies used in the faculty development programme should be aligned with the learning outcomes. They should be authentic and contextually relevant. A lecture based approach to demonstrate the learning that takes place in a small group tutorial in PBL would not be considered 'authentic'. The level and hence outcomes of any faculty development programme will guide the choice of activities, which could range from journal clubs, peer mentoring, portfolio completion to the development of objectives and assessment questions in interprofessional teams.

Thus, in a learner-centered approach to faculty development, participants should be encouraged to negotiate their learning objectives, have hands-on practical experience, collaborate as members of a team, engage in self-directed learning), recognize the assumptions that underlie their beliefs and behaviours, receive and provide feedback, solve problems and transfer this experience to other situations, reflect in- and on-action, alone and with colleagues, engage in self-assessment, and apply what they have learnt to their practice. In terms of implementing a faculty development programme, positive outcomes of a mixed mode approach (role-playing, brainstorming, group discussions, practice, and feedback) to faculty development [14]

\section{Step 5: Final implementation:}

Questions that need to be answered at this stage include:

a. Should faculty development be multidisciplinary?

b. Is there protected time?

c. Are the goals and outcomes being met?

d. If not, is the programme sufficiently adaptable to accommodate unanticipated shortcomings?

Faculty development should use collaborative team work, allowing individuals to reflect on their practice and receive feedback from peers.

FD program has to be adopted by the dean office or the faculty board. From there a special committee may be assigned to look after this program. Whether this committee is under the umbrella of the Department of Medical Education, if exist, or under the responsibility of Postgraduate Department, it does not matter. The members of the committee should be highly motivated and should realize the importance and deeply understand the mission of FD program. It would be much desirable if they had some background on medical education in general and on FD in particular [11]. 


\section{Evaluation and feedback (Step 6):}

Step 6: Evaluate programme effectiveness and provide feedback: Although evaluation is an important aspect of faculty development, it is probably the most neglected. Evaluation of a faculty development programme should be linked to the desired outcomes. Critical questions about measuring programme effectiveness need to be asked and answered during the planning stage, when the objectives are agreed upon. As already alluded to, the poor documentation of longterm and meaningful outcomes may, apart from inherent difficulties of measuring higher level outcomes, relate to inappropriate evaluation tools, amongst a number of other factors (e.g. insufficient resource allocation). To date, evaluation of faculty development has been largely quantitative. While this may be appropriate for lower level outcomes (e.g. participant satisfaction) in Kirkpatrick's [14] model, higher order outcomes require more qualitative measures [11].

Kirkpatrick's four-level model for assessing training effectiveness: By far the most popular approach to the evaluation of training in organizations today is Kirkpatrick's [15] framework of four 'levels' of criteria. Kirkpatrick's $[14,15]$ training evaluation model delineates four levels of training outcomes: reaction, learning, behavior, and results.) Evaluation should always begin with level one, and then, as time and budget allows, should move sequentially through levels two, three, and four.

\section{Tutor training experience in The Faculty of Medicine, Suez Canal University}

In the FOM-SCU the educational blocks are integrated; block is multidisciplinary, a tutor will be an expert in particular problems and non-expert or semi-expert in other problems included in the single block. Most of Phase II tutors were young graduates from the school assistant academic staff -SCU. The junior academic staffs at FOM-SCU take educational responsibilities such as small group facilitation, field tutoring and skill lab, tutoring early on their professional life, they are involved in educational practices as early as they recruited. This is different from the policies in other faculties of medicine, which stat that only faculty with a doctorate degree can be involved in students' education. This difference is due to the educational strategy at FOMSCU, which is problem based, community-oriented, and communityBased.

The study was conducted in the academic years 2010-2011, 20112012 and 2012-2013. The 6-year undergraduate medical curriculum is divided into phase I (year 1), phase II (years 2 and 3 ) and phase III (years 4,5 and 6). The phase II program is organized around twelve integrated organ/system units, where PBL is the main strategy of learning. In a 2-hour tutorial sessions about 8-10 students meet twice per week. In the first tutorial session (brainstorming session), students discuss the presented problem by going through the steps of problem solving, and then they go to collect information regarding this problem based on the learning objectives. The students meet again in the second session which is called (the debriefing session) to apply their information on the presented problem.

Our main challenge here was to develop a tutor training workshop that motivate tutors to their role as class tutor and shift their mindset from traditional role of academic staff as information provider to the new role as a facilitator and discussion leader, and developing an interactive learning environment in the workshop, makes it more relevant to Phase II tutor needs, identify the problems they face in moderating the PBL sessions and tried to solve it, to enhance educational effectiveness of the PBL sessions.
This study passed through three stages:

a. Stage 1: Preparation.

b. Stage 2: Design.

c. Stage 3: Implementation and Evaluation.

Tutor training workshop followed six steps approach to faculty development, the first step was needs assessment, and it was done by distributed self-administered questionnaire to assess the needs of the Phase II PBL class tutors for tutor training, this questionnaire included demographic data (gender, specialty, academic rank, school of graduation, previous years of experience as PBL tutor, etc....). Part of the questionnaire was concerned with tutor training, their previous experience and benefit of attending a tutor training workshops; another part was concerned with the process of PBL sessions and tutors competences (self assessment) in managing PBL process. This study passed through three stages:

Stage 1: "Preparatory": Aiming for excellence in tutoring and considering the importance of tutors for student learning; a tutor training workshop was designed and implemented. This training was designed after the conduction of needs assessment of phase II PBL class tutors; determining their needs for a tutor training. First needs assessment questionnaire was designed and distributed to comprehensive sample of Phase II PBL class tutor in the academic year (2010-2011), in order to determine their needs for a tutor training and identify the problems they may face in moderating the sessions, A section for suggestions and free comments was included in this needs assessment questionnaire. These suggestions were of great benefit in constructing the training workshop

The following were the steps of the first phase:

1. An unstructured interview was held with the Faculty Dean and Vice Dean of Education and Students Affairs to discuss with them the need for designing a tutor training workshop,

2. Literature review for the important and relevant topics to included in a tutor training workshop;

3. Designing the needs assessment questionnaire (self administered questionnaire was designed by the researcher) for both tutors and DELPHI sample of medical education experts eleven judges (medical education experts) were asked to suggest important themes for the workshop.

4. Validated the questionnaire by medical education experts and the study supervisors;

5. Determined needs assessment of targeted population (Phase II class tutors).

Stage 2: “Design":

1. Priorities important topics for the tutor training workshop in the FOM-SCU.

2. Develop tutor training workshop goal and objectives.

3. Designed a tutor training workshop program.

4. Participants for this study were randomly assigned to experimental groups (intervention and control groups).

5. The intervention group received a tutor training and the control group received no intervention. 
The comparison (control) group is selected so that its characteristics matching those of the intervention group as closely as possible. The degree of similarity between the groups is determined through preprogram comparison; this decreases the threats of internal validity.

\section{Stage 3: "Implementation and Evaluation":}

6. Intervention group received tutor training, one week before the start of brain storming sessions.

7. Tutors' self assessment was assessed before the intervention for both intervention and control group one month before the intervention and three months after the intervention Dolmans and Ginns [16] validated questionnaire were used for tutors self assessment with minor modifications.

8. Student satisfaction about the performance of PBL class tutors was assessed one month before the intervention for both the intervention and control groups and three months after the intervention; this reflected the impact of the tutor training on the performance of the PBL class tutors.

9. Program evaluation of the designed intervention was toke place according to Kirkpatrick's [14] evaluation of educational intervention; Kirkpatrick level one (response) was evaluated by assessing tutors satisfaction with the training workshop. Also Kirkpatrick's level two "learning". This level was assessed by paper and pencil knowledge test (pre-and post- test) distributed at the beginning of the workshop and again at the end of the workshop, Kirkpatrick's level three; this include change in behavior of tutors (to what extent did tutors change their behavior back in the PBL sessions as a result of the intervention) was evaluated from tutor point of view (tutor self assessment) and from students point of view students evaluate the performance of their class tutors.

\section{Results}

\section{Section I: Needs assessment of targeted population}

Phase II class tutors were selected, because students in this phase are still novice, they arrive to begin a PBL curriculum with little prior knowledge, and into a self-directed learning environment which is unstructured, the novice student with little prior knowledge on which to build a scaffolding for new knowledge needs guidance and relies on the competent tutor, students will turn to their tutors for help and direction.

Needs assessment of targeted population (Phase II $\left(2^{\text {nd }}\right.$ and $3^{\text {rd }}$ year) class tutors): As regards the attendance of tutor training workshops, Figure 4 shows that 22 tutors (55\%) of the study sample for needs assessment attended a tutor training workshop about the role of the tutor in Problem Based learning in The FOM-SCU these workshops were obligatory one to all novice tutors preparing them for the role of PBL class tutor.

As regards tutors' opinions about usefulness of tutor training workshop, Figure 5 shows that $54.5 \%$ of the tutors benefited from attending a tutor training workshop about the role of the tutor in Problem Based Learning, 9\% of the study population found it useless.

Concerning tutors who facing difficulties in managing group dynamics, Figure 6 shows that $60 \%$ of the study population were facing difficulties in managing group dynamics.
Phase II class tutors in The FOM-SCU suggested some topics for the workshop like group dynamics, dealing with different personalities, steps of PBL tutorial, role of the tutor as a facilitator, providing constructive feedback, different questioning techniques and asking open ended, non directive questions.

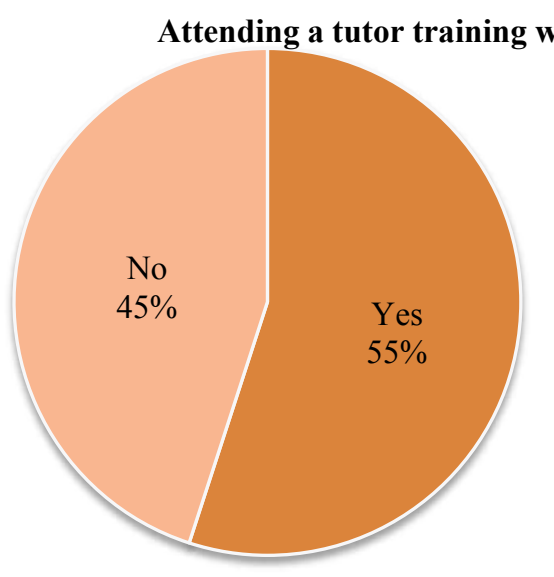

Figure 4: Percent of Phase II class tutors' who attended tutor training workshops $(n=40)$.

\section{Benefit of attending turor training wosrkshop}

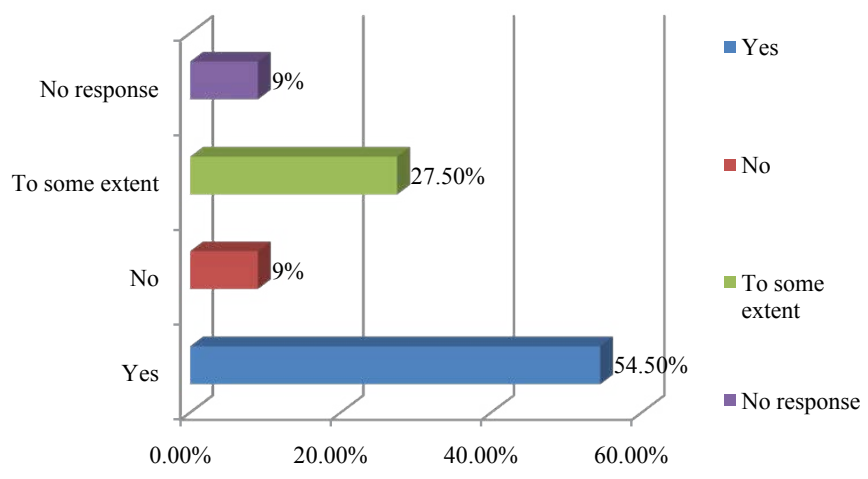

Figure 5: Percent of Phase II class tutors who benefited from attending a tutor training workshop $(n=22)$.

\section{Facing difficulties in managing group dynamics}

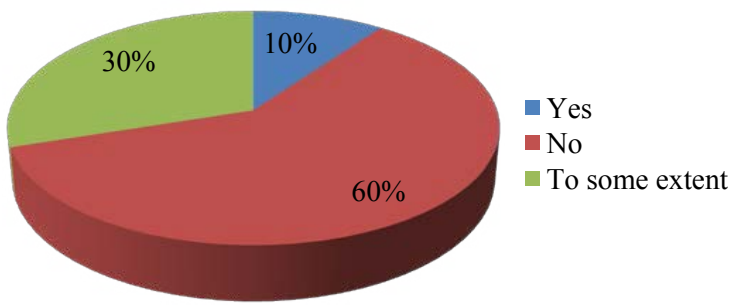

Figure 6: Percent of Phase II class tutors who face difficulties in managing group dynamics. 


\section{Section II: Needs assessment of Medical education experts (DELPHI technique for the designed workshop)}

The topics related to the workshop were selected by using DELPHI [17] method to assess their relevance. DELPHI technique uses a series of judges as experts in order to define or evaluate components of a theoretical issue and to develop consensus between judges. Here, eleven judges, two professors, one assistant professor, and eight Medical education experts (five had $\mathrm{PhD}$ degree in medical education, three had masters in medical education), were included in the Delphi they were all from FOM-SCU faculty. Delphi technique took two rounds.

The goal of the faculty development tutor training workshop was enhancing the instructional effectiveness of Phase II Class tutors; for tutoring the PBL sessions in more competent manner.

Objectives of the workshop:

1. List steps of Problem solving in PBL.

2. Discuses role of chairperson, scribe and other students in PBL sessions.

3. Explain the role of the tutor in PBL.

4. Applying questioning techniques while tutoring in $\mathrm{PBL}$ sessions.

5. Applying the principles of group dynamics.

6. Directing students to create a concept map for the problems.

7. Managing time during PBL sessions effectively.

8. Deal effectively with common difficult tutorial situations.

9. Assess students in PBL.

10. Provide constructive feedback.

DELPHI round 1: Literatures were reviewed for tutor faculty development program and important themes to be included in it, a comprehensive list were made and opinions of the experts were collected, considering the limited time (only one day tutor training workshop) only the most important themes were included in the workshop,also themes that would help to facilitate the PBL sessions process. The questionnaire was relatively unstructured with openended questions to increase the richness of the data collected and allow the participants relatively free scope to elaborate on the topic under investigation.

First topics for the workshop were sent to the eleven judges (Medical Education Experts).

Analysis of first round responses: Each received response from round 1 was listed as a separate item. Hence, a total of 10 ideas and suggestions were generated. The study researcher; the Delphi coordinators, reviewed the data, combined the same ideas and clustered similar ideas together into emerging themes. Then themes were named, and wrote a brief statement describing the essential nature of each theme. In the first DELPHI cycle, they ranked the important topics for the workshop, and the relevance of the theme to the tutors, new themes were added to the list.

DELPHI 2 round: In the second round participants were presented with the 25 items organized beneath the 10 themes generated from Round 1. Consistent with a Delphi process, participants were asked to nominate the importance of the items on a 10 point scale, ranging from completely disagree to completely agree. They were required to use whole numbers, use all 10 points, no more than 10 points.

Analysis of second round responses: To analyze the gathered data, the total mean score of each item was calculated. Total mean score of 1 to 5 was considered as disagreement and total mean score of 6 to 10 was regarded as agreement with each item.

Table 1 shows total mean points allocated to agreed items in Round 1 and 2 regarding important themes for one day tutor training workshop which included introduction to PBL as educational strategy, steps of PBL tutorial sessions, integration of basic medical sciences through PBL, role of chairperson, scribe and other students in PBL sessions, group dynamics, facilitative skills of the tutor, role of the tutor in PBL, self- and peer-assessment, triple jump assessment, importance of creating a concept map for the problem, simulation for PBL sessions, clinical reasoning process.

Training for intervention group tutors was held at the Faculty of Medicine, Suez Canal University. Training was designed in a way to encourage active participation, experiential learning. Tutor training workshop was conducted in one day. It introduced tutors to adult learning principles, small group and PBL, concept mapping, reflective and constructive feedback, group dynamics, questions and questioning techniques, dealing with different personalities and assessment in problem based learning

\section{Evaluation of tutor training workshop:}

Tutors reaction to training workshop (level one): Table 2 shows that all the responses ranged from good to excellent, it shows that more than $64 \%$ of the workshop participants reported excellent convenience of themes to their interest, excellent organization of the workshop, excellent effectiveness of visual aids and handouts and only one participant reported that the instructors presentation styles needed improvement, another two reported that the in the small group task, active participation of every member in the group and group sharing experiences needed improvement. There was an overall satisfaction about the workshop.

Results shows that more than $70 \%$ of workshop participants agreed that the workshop furthered their understanding of PBL as educational strategy and their role as tutors, also $57 \%$ of them strongly agreed that the workshop furthered their understanding of tutorial group dynamics, and more than $67 \%$ strongly agreed that that the workshop furthered their understanding about assessment in PBL.

Only sublevel 2B (modification of knowledge) was evaluated in level 2 of Kirkpatrick's model. This was evaluated by measuring differences in the results of the test (pre- and post- test) before and after conduction of the workshop for intervention group only. Table 3 shows that the mean of the pretest was 5.42 and the mean of posttest was 7.1, this table also shows that there was a statically significance difference between the results of the pre-and the post-tests for the workshop at $\mathrm{p} \leq 0.05$.

\section{Tutors performance evaluation:}

Class tutors self-assessment: Concerning tutors self assessment of their overall performance during facilitating PBL sessions, Table 4 shows that there is a statistically a significant difference between the control and intervention groups in post self evaluation regarding tutors overall self assessment of their performance as class tutors.

Phase II Students evaluation of tutors' performance: Evaluation 


\begin{tabular}{|c|c|c|c|c|c|}
\hline \multirow{2}{*}{\multicolumn{2}{|c|}{ Themes }} & \multicolumn{2}{|c|}{ First DELPHI round } & \multicolumn{2}{|c|}{ Second DELPHI round } \\
\hline & & Mean & SD & Mean & SD \\
\hline 1 & Facilitative skills of the tutor & 7.86 & 2.014 & 9.65 & 1.426 \\
\hline 2 & Dealing with common difficult tutorial situations & 8.75 & 1.003 & 9.61 & 0.693 \\
\hline 3 & Tutorial group dynamics & 9.13 & 0.429 & 9.54 & 0.301 \\
\hline 4 & Practical session about how to use the tutor guide & 8.19 & 1.207 & 9.43 & 0.983 \\
\hline 5 & PBL as educational strategy & 8.52 & 1.936 & 9.39 & 0.845 \\
\hline 6 & Assessment in PBL & 7.98 & 0.329 & 9.32 & 0.121 \\
\hline 7 & Importance of creating a concept map for the problem & 8.47 & 0.812 & 9.21 & 0.509 \\
\hline 8 & Providing constructive feedback. & 9.12 & 0.647 & 9.06 & 0.392 \\
\hline 9 & Questions and questioning techniques & 7.38 & 0.812 & 8.95 & 0.890 \\
\hline 10 & Dealing with different personalities & 8.26 & 0.932 & 8.83 & 0.642 \\
\hline 11 & Rule of chairperson, scribe and other students in PBL sessions. & 6.88 & 1.934 & 8.76 & 0.838 \\
\hline 12 & Self- and peer-assessment & 8.26 & 1.958 & 8.75 & 1.106 \\
\hline 13 & Independent learning & 8.06 & 1.048 & 8.30 & 0.727 \\
\hline 14 & Interpersonal communication & 6.45 & 1.344 & 8.06 & 0.365 \\
\hline 15 & Managerial issues related to PBL process & 7.32 & 0.712 & 8.02 & 0.494 \\
\hline 16 & How to handle the evaluation form used to evaluate PBL session and students within. & 7.31 & 1.121 & 7.79 & 0.732 \\
\hline 17 & Formative and summative assessment of $\mathrm{PBL}$ acquired skills & 6.32 & 0.769 & 7.65 & 0.127 \\
\hline 18 & Steps of PBL tutorial session & 7.32 & 1.983 & 7.64 & 0.986 \\
\hline 19 & Clinical reasoning process & 7.01 & 0.902 & 7.45 & 0.248 \\
\hline 20 & Simulation for PBL sessions "ideal one, some pitfalls & 7.03 & 1.042 & 7.25 & 0.736 \\
\hline 21 & Integration of Basic Medical Sciences through PBL. & 6.46 & 2.049 & 7.19 & 1.367 \\
\hline 22 & Time management in PBL tutorials. & 5.97 & 0.913 & 7.11 & 0.546 \\
\hline 23 & Orientation of basic skills expected from brain storming sessions and debriefing sessions. & 6.19 & 0.748 & 7.03 & 0.819 \\
\hline 24 & Time management in PBL tutorials. & - & - & 7.00 & 1.385 \\
\hline 25 & Assessing clinical reasoning & - & - & 6.98 & 1.804 \\
\hline
\end{tabular}

Table 1: Tutor training workshop themes from Delphi team members' points of view.

\begin{tabular}{|c|c|c|c|c|c|c|c|c|c|c|c|}
\hline \multirow{3}{*}{\multicolumn{2}{|c|}{ Questions }} & \multicolumn{10}{|c|}{ Responses } \\
\hline & & \multicolumn{2}{|c|}{ Excellent } & \multicolumn{2}{|c|}{ Very good } & \multicolumn{2}{|c|}{ Good } & \multicolumn{2}{|c|}{ Needs mprovement } & \multicolumn{2}{|c|}{ Bad } \\
\hline & & No & $\%$ & No & $\%$ & No & $\%$ & No & $\%$ & No & $\%$ \\
\hline \multirow{4}{*}{ 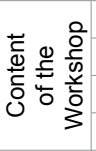 } & Coverage of useful items & 20 & $55.55 \%$ & 8 & $28.57 \%$ & 0 & 0 & 0 & 0 & 0 & 0 \\
\hline & Convenience to your interest & 18 & $64.3 \%$ & 7 & $25.0 \%$ & 3 & $10.7 \%$ & 0 & 0 & 0 & 0 \\
\hline & Organization of the workshop & 18 & $64.3 \%$ & 7 & $25.0 \%$ & 3 & $10.7 \%$ & 0 & 0 & 0 & 0 \\
\hline & Effectiveness of visual aids and handouts & 19 & $67.9 \%$ & 6 & $21.4 \%$ & 2 & $3.6 \%$ & 0 & 0 & 0 & 0 \\
\hline \multirow{4}{*}{ 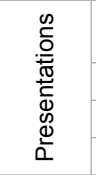 } & Instructors' knowledge & 16 & $57.1 \%$ & 11 & $39.3 \%$ & 1 & $3.6 \%$ & 0 & 0 & 0 & 0 \\
\hline & Instructors' presentation style & 16 & $57.1 \%$ & 8 & $28.6 \%$ & 3 & $10.7 \%$ & 1 & $3.6 \%$ & 0 & 0 \\
\hline & Coverage of the material & 16 & $57.1 \%$ & 6 & $21.4 \%$ & 4 & $21.4 \%$ & 0 & 0 & 0 & 0 \\
\hline & Response to questions & 14 & $50.0 \%$ & 10 & $35.7 \%$ & 2 & $7.1 \%$ & 0 & 0 & 0 & 0 \\
\hline \multirow{4}{*}{ 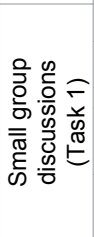 } & Size of the group & 16 & $57.1 \%$ & 7 & $25.0 \%$ & 5 & $17.9 \%$ & 0 & 0 & 0 & 0 \\
\hline & $\begin{array}{l}\text { The selected scenarios representing common difficult tutorial } \\
\text { situations }\end{array}$ & 16 & $57.1 \%$ & 8 & $28.6 \%$ & 4 & $14.3 \%$ & 0 & 0 & 0 & 0 \\
\hline & $\begin{array}{c}\text { Active participation of every member in the group and sharing } \\
\text { experiences }\end{array}$ & 12 & $42.9 \%$ & 7 & $25.0 \%$ & 7 & $25.0 \%$ & 2 & $7.1 \%$ & 0 & 0 \\
\hline & $\begin{array}{c}\text { Suggested strategies that tutor will use to deal with these } \\
\text { situations. }\end{array}$ & 16 & $57.1 \%$ & 8 & $28.6 \%$ & 4 & $14.3 \%$ & 0 & 0 & 0 & 0 \\
\hline
\end{tabular}

Table 2: Frequency distribution of tutors according to their reactions about tutor training workshop $(n=28)$.

of tutors' performance during facilitating the PBL sessions was one of the tools to evaluate the outcomes of conducting a tutor training workshop, students were asked to evaluate their tutors' performance before and after the implementation of tutor training workshop (Kirkpatrick level 3).

Results shows that there is a statistically significant difference between control and intervention groups concerning tutors role in clarifying difficult terminologies, facilitating problem identification, problem analysis, helping students generating hypothesis and teaching students how to construct a (concept map) for the problem.

There was a statistically significant difference between control and intervention groups concerning tutors' questioning techniques; tutors in the intervention group asked more non directive, open-ended questions that stimulated the discussion.

As regards students overall satisfaction with their tutors performance during facilitating PBL sessions Table 5 shows that there is statistically significant difference between control and intervention groups in the post intervention mean scores.

\section{Discussion}

The preparation of this study started with needs assessment of targeted population, The Continuing Medical Education (CME) 
Citation: El-Aziz El Naggar MAA, Maklady FAH, Hamam AM, Omar AS (2013) Effectiveness of Implementing a Tutor Training Workshop for Problem Based Learning Class Tutors at the Faculty of Medicine, Suez Canal University. Intel Prop Rights 1: 104. doi:10.4172/2375-4516.1000104

Page 8 of 10

\begin{tabular}{|c|c|c|c|}
\hline Workshop & Pretest Mean \pm SD & Post-test Mean \pm SD & p-value (t-test) \\
\hline Tutor training workshop & $5.42 \pm(1.98)$ & $7.1 \pm(1.36)$ & $0.02554^{*}$ \\
\hline
\end{tabular}

Statistically significance at $\mathrm{P} \leq 0.05$

Total number of 28 tutor (intervention group).

Table 3: Outcomes of the tutor training workshop (result of the pre- and post-test).

\begin{tabular}{|c|c|c|c|c|c|c|}
\hline \multirow{5}{*}{$\begin{array}{l}\text { The average score for the overall } \\
\text { performance of the tutor }\end{array}$} & \multicolumn{2}{|c|}{ CONTROL GROUP (n=28) } & \multicolumn{2}{|c|}{ INTERVENTION GROUP $(\mathrm{n}=28)$} & $\mathrm{p}$-value (t-test) & $\mathrm{p}$-value (t-test) \\
\hline & Pre & Post & Pre & Post & \multirow{2}{*}{ Pre Baseline } & \multirow{2}{*}{ post } \\
\hline & Mean \pm SD & Mean \pm SD & Mean \pm SD & Mean \pm SD & & \\
\hline & 6.22 & 6.54 & 6.9 & 7.67 & \multirow{2}{*}{0.0823} & \multirow{2}{*}{$0.02352^{*}$} \\
\hline & \pm 2.81 & \pm 2.02 & \pm 2.12 & \pm 1.20 & & \\
\hline
\end{tabular}

Statistically significance at $p \leq 0.5$

Table 4: Comparison between tutors' self assessment average score for the overall performance of the intervention and control groups of the tutor after the tutor training workshop ( $n=28$ per group).

\begin{tabular}{|c|c|c|c|c|c|}
\hline \multirow{2}{*}{$\begin{array}{c}\text { Students' overall } \\
\text { evaluation of tutors' } \\
\text { performance }\end{array}$} & CONTROL GROUP $(\mathrm{n}=70)$ & \multicolumn{2}{|c|}{ INTERVENTION GROUP $(\mathrm{n}=70)$} & $\mathrm{p}$-value (t-test) \\
\cline { 2 - 5 } & Mean \pm SD & Mean \pm SD & Mean \pm SD & Mean \pm SD \\
\cline { 2 - 5 } & 2.49 & 2.86 & 2.47 & 3.38 \\
\hline
\end{tabular}

(On a likert scale from 1-5)

Table 5: Comparison between students' in the intervention and control groups opinions about overall evaluation of tutors' performance.

literature suggests that learning is more likely to lead to changes in practice when needs assessments are conducted, when education is linked to practice, and when personal incentives drive learning [13].

Fifty five Phase II tutors responded to the questionnaire, representing a response rate of $72.7 \%$. Tutors summarize the causes of dissatisfaction with attending formal training about tutor role in PBL curriculum at the FOM-SCU, that the content of the workshop is not relevant, incongruent method of instruction, shortage of time, lack of simulation or hands on training (it was only a didactic lecture), and obligatory of the attendance, for these reasons, we decided to conduct a practical training workshop that incorporated adult learning principles (was relevant and interactive); experiential learning; arose from needs assessments; rewarded participation; encourage active participation; had clear goals and a theoretical framework; and offered a range of educational methods (such as face-to-face instruction and role-play).

Questionnaire included open-ended questions to identify aspects for which they needed specific training, tutors suggested some topics for the workshop like group dynamics, dealing with different personalities, steps of PBL tutorial, role of the tutor as a facilitator, providing constructive feedback, different questioning techniques, Holmes and Kaufman [18] and Tipping et al. [19] emphasized the important that tutors should be asked with open-ended questions to identify aspects for which they needed specific training and teaching situations they found difficult to manage.

Duration of the workshop was one day, Steinert et al. [20], conducted a professional development program (PDP) for tutors, The major aim was to build stronger facilitation skills so that tutors learning new skills and extending their original basic skills. PBL tutors required to attend an initial training workshop of $5 \mathrm{~h}$ duration. They outlined the principles for conducting a professional development program (PDP).

One day workshop was planned to be held. The planned workshop program based on the medical education experts collected opinions about the important themes to be addressed during one day tutor training workshop; opinions were collected through a DELPHI technique, DELPHI was of two rounds. The workshop was designed to be compatible with adult learning principles, experiential, learnercentered learning, and focused on active participation.

Topics of workshop were prioritized, eleven judges (medical education experts) were asked to suggest important themes for the workshop; goal of the workshop was enhancing the instructional effectiveness of Phase II Class tutors to be able to tutor the PBL sessions in more competent manner. Topics were grouped according to its similarity and relevance; first priority was devoted to facilitate skills of the tutor; the importance of this topic was emphasized by Baroffio et al. [21], they pointed out that effective tutor training workshops are essential to develop and sustain the quality of faculty's teaching skills. They conclude that in an integrated problem-based curriculum, tutors needs to further develop their skills in facilitating students' content learning, small-group functioning, and group dynamics.

A situation-based approach was used in our study, to assist tutors in developing advanced strategies to facilitate small-group functioning. Tutor training workshop small group task was, pre-selected scenarios representing common difficult tutorial situations (i.e. a disruptive or silent student, a non-responsive group, dominant students. . .), and we asked tutors to analyze, discuss these situations, describe specific interventions used in response, and assess the success of each intervention strategy, and share strategies that they would use to deal with these situations.

Evaluation of a faculty development programme should be linked to the desired outcomes. Critical questions about measuring programme effectiveness need to be asked and answered during the planning stage, when the objectives are agreed upon [12]

The first level of Kirkpatrick's model is reaction, and it was assessed by workshop evaluation form using a 5-point likert scale; "reaction" of the tutors in the intervention group towards the workshop was assessed. The results have shown overall satisfaction with the organization, content, and small group task of the workshop, with most responses being either "excellent" or "very good". The importance of the first level of Kirkpatrick's model was emphasized by Baroffio et al. [21] they measure tutors' satisfaction about the workshop usefulness and of their 
improvement in tutorial facilitation skills, in this study tutors judged the importance and usefulness of tutor training workshop, workshop providing them with new teaching strategies and reported improvement in their tutorial skills. While we strive to measure 'meaningful' and 'long-term' outcomes of faculty development, Steinert [22] has pointed out that despite participant satisfaction being assigned to the lowest level on Kirkpatrick's [14] model, it is nevertheless an important consideration in faculty development. She stated that if participants do not believe that their time and efforts were well spent, they may not sign up for further faculty development sessions, just as the travelers on the train journey.

Steinert et al. [20] in a systematic review of faculty development, participants consistently found faculty development programs important, acceptable, useful and relevant to their objectives, also participants reported positive changes in attitudes toward faculty development and teaching, enhance in knowledge of educational principles and gains in teaching skills.

More than $70 \%, 57 \%$, and $67 \%$ of workshop participants agreed that workshop furthered their understanding about PBL as educational strategy; their role as a tutor, tutorial group dynamics and assessment in PBL, respectively. In a study held by Baroffio et al. [21], the tutors agreed that the workshop furthered their understanding of the tutorial group functioning process (mean $4.19 \pm 0.82$ ), and provided useful strategies to improve content knowledge with the group of tutors in their teaching unit (mean $4.28 \pm 0.95$ ), with is consistent with the results of study held with Nasmith et al. [23], the study indicated that behaviors can change following one half-day workshop, this is also matching with our study results.

\section{The second level in Kirkpatrick's model is "learning".}

This level was assessed by paper and pencil knowledge test (pre-and post- test) distributed for intervention group only at the beginning of the workshop and again at the end of the workshop. The pre-and posttest was scored out of 10 . The results of the study showed a statistically significant difference between the results of the pre- and post- test ( $\mathrm{p}$ $\leq 0.05)$. The mean of the pre-test was $5.42 \pm$ (1.98), while the mean of the post-test results was $7.1 \pm(1.36)$. Similar results were shown in the study held by Farghaly et al. [24] for FD for junior academic staff at FOM-SCU, they assessed junior staff by a pre-post test, with 20 item test and showed mean score in the post test for the theme "communication skills and group dynamics" $17.87 \pm(1.62)$. Although most of the tutors were graduated from FOM-SCU (PBL School) which exposed them to the experiences in PBL tutorial as students, and they received an obligatory training that takes place at the University as part of the prerequisites for promotion, the themes of the workshop was new for most of them like assessment in PBL, facilitative skills of the tutors and providing constructive feedback, group dynamics, concept mapping, clinical reasoning. This explains the improvement in knowledge of the tutors in these areas.

Many similar studies were held to evaluate the effectiveness of tutor training program. One of them is a study held by John et al. [25] they had designed four PBL tutor training workshops in the University of Hawaii A. Burns school of Medicine. Eighty eight faculty volunteers each answered a 20 item multiple choice questions testing their knowledge of PBL both before and after their participation in the workshop. Questions were assessing the faculty trainees' PBL knowledge and skills, the post-test results showed improvement of tutors knowledge and skills related to tutor role after the workshops. Another similar study is the study held by Baroffio et al. [21], who conducted a tutor training workshop, they tailored the workshop to the needs of the tutors in the context of their teaching unit, they compared change in knowledge acquisition on several tutorial skills (overall performance, problem-content knowledge, skill in guiding students through the PBL process, and ability to facilitate student participation) between workshop attendance and non attendance, and between the workshop attendance base line knowledge and one month and one year after the workshop, they concluded that the workshop improved tutors' knowledge of the problem content of the teaching unit and their ability to guide the learning of their students.

The same results was documented in a study held by Mariana et al. [26] they assessed the outcomes of a FD program in medicine and pediatrics, they assessed clinical teaching effectiveness in Cleveland clinic for both experimental (pre-post test) and control group (posttest only), their results showed statistically significances differences between experimental and control group and between experimental group before and after the workshop ( $\mathrm{p}$-value $=0.002$ ) showing positive impact of the FD program, their results cannot be accurately compared to ours, since we only assess the experimental group (pre-post test), we did not assessed the control group (tutor who did not attend the workshop). Another study held by Baroffio et al. [21] found that tutors participation in tutor training workshops improved participants' understanding of the PBL principles as educational strategy, teaching strategies, knowledge of problem content, and ability to facilitate student learning. Steinert et al. [21] stated that where formal tests of knowledge were used, comparing pre-post scores shows significant gains (Kirkpatrick level two). Changes in teaching behavior were consistently reported by participants and were also detected by students (Kirkpatrick level three).

As regards level 3 in Kirkpatrick's [14] model, Dolmans et al. [16] standardized, validated and reliable tutor self assessment questionnaire was distributed to the Phase II class tutors in both control and intervention groups, for obtaining rating of their self assessment.

Results of the questionnaire showed improvement of intervention group tutors' performance in the area of constructive active learning, self- directed learning, collaborative learning, and intra-personal behavior as tutor. Improvement was in the item related to tutors helping students more to search for explanations during discussion, summarize what they had learnt in their own words, participate actively in the PBL sessions, generate clear learning objectives by themselves, search for various resources by themselves, and create a concept map for the problem. There were a statistically significance differences between both groups in post self assessment evaluation ( $\mathrm{p} \leq 0.05$ in all items).

The average score for the overall performance of the tutor was (7.67 $\pm 1.20)$ in the intervention group compared with control group (6.54 \pm 2.02 ), this was parallel with the results of the study held by Dolmans et al. [16].

As regards level 3 in Kirkpatrick's [14] model, behavior outcomes address either the extent to which knowledge and skills gained in training are applied on the job or result in exceptional job-related performance. Evaluation of tutors' performance during facilitating the PBL sessions was one of the tools to evaluate the outcomes of implementing a tutor guide, students were asked to evaluate their tutors' performance before and after the implementation of tutor training workshop, for both intervention and control group pre-post intervention.

Analysis of students' results revealed improvement of tutor performance. Results of tutor self assessment and students rating of 
Citation: El-Aziz El Naggar MAA, Maklady FAH, Hamam AM, Omar AS (2013) Effectiveness of Implementing a Tutor Training Workshop for Problem Based Learning Class Tutors at the Faculty of Medicine, Suez Canal University. Intel Prop Rights 1: 104. doi:10.4172/2375-4516.1000104

Page 10 of 10

tutor performance shows that both results are nearly equal for the intervention group, tutors performance mean scores from students point of views was $(78.14 \pm 12.64)$, tutor overall self assessment mean score $(75.78 \pm 12.30)$. We found that tutor self assessment and students rating are matching. In a study held by Irby et al. [27], they found that self-reposts and observable behavior matched.

Studies investigating the related factors to tutor performance have found that a tutor's performance is also dependent on the quality of the cases, structure of PBL courses, and link with students' level of prior knowledge, and the functioning of tutorial groups [28].

Finally, students' ratings revealed that tutors improved their ability in facilitating student participation, and tutors assessed themselves as being better facilitators of small-group functioning after the workshop.

\section{Conclusion}

Our study contributes to the body of research that highlights the importance of faculty development programs that provide training in effective tutoring techniques.

The study concluded that tutor training workshop was effective in improving tutor facilitation skills in the areas of constructive active learning, self- directed learning, collaborative learning, intra-personal behavior as tutor, and increase educational effectiveness of the PBL sessions from students' point of views. Tutor training workshop enhanced tutor performance in intervention group compared to the control group. The tutor training workshop increases tutors' self satisfaction with their performance and enhances students' satisfaction with tutor performance. Tutor training was effective as it incorporated adult learning principles (was relevant and interactive); experiential learning; arose from needs assessments; rewarded participation; encourage active participation; had clear goals and a theoretical framework.

\section{References}

1. Maklady F, Talaat W, Hosny S, Abd-Allah E, Makhlouf L (1995) Priority Health Problems in Problem-Based Learning: The Suez Canal Experience. Annals of Community-Oriented Education 8: 183-194.

2. Barrows HS (1982) A learning Method Based on the Principle of Using Problems as a Starting Point for the Acquisition and Integration of New knowledge. Spring Publication Co, New York, USA

3. Azer SA (2001) Problem Based Learning: A Critical Review of Its Educational Objectives and the Rational for Its Use. Saudi Med J 22: 299-305.

4. Newble D, Cannon R (1995) A Handbook for Teaching in Universities and Colleges. Kogan Page, London, UK.

5. Boud D, Feletti G (1997) The challenge of problem-based learning. Routledge, London, UK.

6. Dolmans D, Snellen H (2007) Problem Construction, Problem Based Learning.

7. Harden R, Crosby J (2000) AMEE Guide No. 20: The good teacher is more than a lecturer - the twelve roles of a teacher. Medical Teacher 22: 334-347.

8. Andrews M (1996) Problem-based learning in an undergraduate nursing programme: a case study. Journal of Advanced Nursing 23: 357-365.

9. Diana WF (2003) ABC of learning and teaching in medicine: Problem Based Learning. British medical Journal 326: 328-330.

10. Branda LA, Scriarra AF (1995) Faculty Development for Problem Based Learning. Annals of Community-Oriented Education 8: 197-199.
11. Dolmans DH, Gijselaers WH, Moust JH, de Grave WS, Wolfeagen IH et al., (2002) Trends in research on the tutor in problem-based learning: conclusions and implications for educational practice and research. Med Teach 24: 173180

12. Amin Z, Hoon Eng K, Gwee M, Chay Hoon T, Dow Rhoon K (2006) Addressing the needs and priorities of medical teachers through a collaborative intensive faculty development programme. Med Teach 28: 85-88.

13. Dolmans DH, Wolfhagen IH, Scherpbier AJ, Vleuten CP (2001) Relationship of Tutors' Group-dynamics Skills to Their Performance Ratings in Problem-based Learning. Acad Med 76: 473-476.

14. Kirkpatrick DL (1994) Evaluating Training Programs: The Four Levels. BerrettKoehler Publishers, San Francisco, CA, USA.

15. Kirkpatrick D (1997) Techniques for evaluating programs, part of Great Ideas Revisit desires in Training \& Development 54-59.

16. Dolmans $D H$, Ginns $P$ (2005) A short questionnaire to evaluate the effectiveness of tutors in PBL: validity and reliability. Med Teach 27: 534-538.

17. Wholey JS, Hatry HP, Newcomer KE (2004) Handbook of Practical Program Evaluation. Jossey-Bass, San Francisco, USA.

18. Holmes DB, Kaufman DM (1994) Tutoring in problem-based learning: a teacher development process. Medical Education 28: 275-283.

19. Tipping J, Freeman RF, Rachlis AR (1995) Using faculty and student perceptions of group dynamics to develop recommendations for PBL training. Acad Med 70: 1050-1052.

20. Steinert Y, Mann K, Centeno A, Dolmans D, Spencer J, et al., (2006) A systematic review of faculty development initiatives designed to improve teaching effectiveness in medical education: BEME Guide No. 8. Med Teach 28: 497-526.

21. Baroffio A, Nendaz MR, Perrier A, Layat C, Vermeulen B, et al., (2006) Effect of teaching context and tutor workshop on tutorial skills. Med Teach 28: 112119.

22. Steinert Y (2005) Staff development for clinical teachers. The Clinical Teacher 2: $104-110$.

23. Nasmith L, Mcalpine L, Franco ED (1995) Teaching by case discussion: a faculty development intervention. Med Teach 17: 419-430.

24. Farghaly A, Talaat W, Makklady F, EI Wazir Y (2011) Design and implementation of a quasi -experimental study for faculty junior academic staff development program at The Faculty of Medicine, Suez Canal University. Journal of Cairo University.

25. McDermott JF Jr, Anderson AS (1991) Retraining faculty for the problem based learning curriculum at the University of Hawii, 1989-1991. Acad Med 66: 778779.

26. Hewson MG, Copeland HL (1999) Outcomes assessment of faculty development program in medicine and paediatrics. Acad Med 74: 568-571.

27. Irby DM, Vontver LA, Stenchever MA (1982) Improving teaching in a multisite clerkship: faculty-development workshops. J Reprod Med 27: 307-310.

28. Chung EK, Hitchcock MA, Oh SA, Han ER, Woo YJ (2011) The relationship between student perceptions of tutor performance and tutors' background in problem-based learning in South Korea. Int J Med Educ 2: 7-11. 